\title{
NON-AGENT SUBJECTS AND SLOPPY READINGS
}

\author{
FUMIO MOHRI \\ Kurume Institute of Technology
}

\begin{abstract}
The purpose of this paper is to show that certain pronouns that are anaphoric on non-Agent subjects should be treated as phonologically realized traces, which are left within VP after subject raising. This idea is based on Hasegawa (2001), which we will support by focusing on the analysis of comparative VP ellipsis. More precisely, we will argue that such pronouns are interpreted as pure variables in the semantics because they are traces in syntactic structure.*
\end{abstract}

Keywords: non-Agent subjects, comparative VP-Ellipsis, sloppy reading, resumptive pronoun

\section{Introduction}

In recent proposals such as Chomsky $(1995,1998,2001)$ and Collins (1997) an external argument is generated in Spec of $v \mathrm{P}$, and $v$ takes VP as its complement. Specifically in Collins' system, where the head of $\nu \mathrm{P}$ is specified for $[ \pm \operatorname{Tr}($ ansitive $)]$, the derivations and structures of transitive-intransitive pairs are described by a distinction in the feature specification on $v .{ }^{1}$ For transitive verbs, $v$ is specified for $[+\mathrm{Tr}]$ and assigns an external $\theta$-role to its specifier, whether the subject is an Agent or non-Agent. Given this, the English sentences in (1) and the Japanese counterparts in (2) share the same syntactic representation

* I would like to express my profound gratitude to three anonymous $E L$ reviewers for invaluable comments, suggestions, and criticisms. I am also indebted to Yoshi Kubo and Hiroaki Tada for their useful comments and suggestions and Frank Carbullido for answering questions about some English data as well as stylistic suggestions. All remaining errors and inadequacies are, of course, my own.

${ }^{1}$ It is possible to generate $v \mathrm{P}$ without an NP in its specifier. In Collins (1997) the presence of $v$ specified for $[-\mathrm{Tr}]$ is needed in the derivation of noncausatives. Light $v[-\mathrm{Tr}]$ assigns neither an external $\theta$-role nor Object Case.

English Linguistics 19: 1 (2002) 29-53 - 29-

(C) 2002 by the English Linguistic Society of Japan 
and derivation, as illustrated in (3). ${ }^{2}$

(1) a. John broke the glass.

b. The wind broke the glass.

(2) a. John-ga garasu-o kowa-si-ta John-Nom glass-Acc break-tr-past

b. Kaze-ga garasu-o kowa-si-ta Wind-Nom glass-Acc break-tr-past

( 3 )

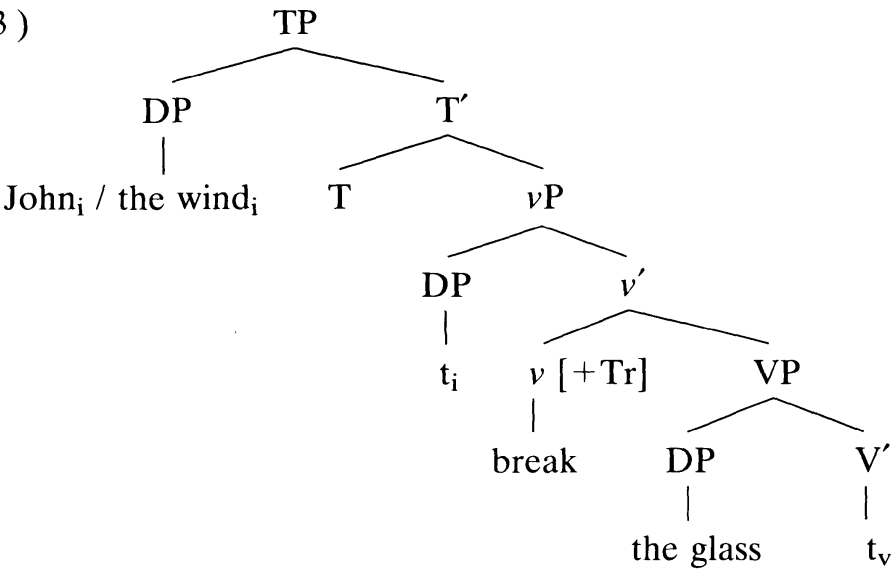

However, Hasegawa (2001) argues that a non-agentive role of a subject is VP-internally assigned. Thus, what is to be assigned in the Spec of $\nu \mathrm{P}$ is Agent only. This view is preferable in terms of UTAH (Uniformity of Theta Assignment Hypothesis), which states that a particular $\theta$-role is assigned in its own syntactic position. In this paper we will argue for Hasegawa's claim that while only agentive arguments are structurally defined as external arguments, non-agentive arguments occur VP-internally, by shedding light on the contrastive behavior between Agent subjects and non-Agent subjects in comparative VP ellipsis.

The argument of this article has to do with the analysis of anaphors in Lidz (2001a, b), where two types of anaphors in natural languages differ in their representative properties in the semantics; one acting as

2 It is assumed from the perspective of distributed morphology that in Japanese the causative morpheme $/ \mathrm{s} /$ is inserted to the $v$ with $[+\operatorname{Tr}]$ later in the derivation. We cannot enter into the discussion here. See Nishiyama (2000) for relevant discussion. 
an independent argument and the other as a pure variable. Basically following Lidz's framework, we will focus on the interpretation of comparative VP-ellipsis constructions and argue that certain pronouns that are anaphoric on non-Agent subjects are taken to be pure variables in semantic formula. As will become clear later, this indicates that they are phonologically realized traces left after the movement of non-Agent subjects to a high position (Spec of TP). It follows then that our discussion here will support Hasegawa's treatment of non-Agent subjects.

Our discussion starts by describing Lidz's partitioning of anaphors in natural languages and pointing out the insufficiency of his analysis in section 2. Section 3 starts with Hasegawa's claim that non-Agent subjects occur VP-internally and resolves the insufficiency pointed out in the previous section. Our discussion will be strengthened by making reference to inalienable possession constructions in section 4. Our core argument throughout this article is that certain pronouns that are anaphoric on non-Agent subjects should be treated syntactically as resumptive pronouns, and as pure variables in the semantics.

\section{Pure Reflexives and Near Reflexives}

Reinhart and Reuland (1993) and Lidz (2001a, b) both show that there are two classes of anaphors in natural languages. ${ }^{3}$ While Reinhart and Reuland's partitioning of anaphors is syntactic, Lidz's is semantic. Morphologically complex anaphors are referred to as SELF anaphors in Reinhart and Reuland and as near-reflexives in Lidz, and morphologically simplex ones as SE anaphors and as pure-reflexives, respectively. Without entering into a discussion of which partition is

3 Reinhart and Reuland (1993) (henceforth, RR) claim that there are two types of anaphors in natural languages: SELF anaphors like English himself and SE anaphors like German sich. The two anaphors differ substantially in their grammatical functions. SELF anaphors carrying the property of +SELF function as reflexivizers, which have the ability of imposing identity on two arguments of a predicate, one of which is the pronoun determiner embedded in the SELF anaphor. By contrast, SE anaphors cannot qualify as reflexivizers due to the lack of +SELF property. As Lidz (2001a) points out, RR's binding conditions make reference only to reflexive marking, but not to the manner of reflexive marking. Along these lines, it would be predicted that all reflexive predicates have the same interpretation at LF. This is not the case. 
more appropriate, we will follow Lidz's semantic analysis (See Notes 4 and 5 for discussion).

In Lidz (2001a, b) anaphors are classified into pure- and near-reflexives, the difference between them shown in (4):

(4) a. $\lambda x[P(x, x)] \quad$ (semantic/pure-reflexive)

b. $\lambda x[P(x, f(x))]$ (near-reflexive)

(Lidz (2001a))

It is important to note that an anaphor that occurs in a pure-reflexive sentence is represented as a pure variable $\mathrm{x}$ (as in (4a)), whereas an anaphor that occurs in a near-reflexive sentence is representationally shown as a function $f(x)$ (as in $(4 b))$. For the semantic representation of (4a) the two arguments of the predicate $P$ are identical. In contrast, (4b) indicates that the second argument is a function taking the first argument as input and returning an entity that is representationally related to that argument. That is, the anaphor and its antecedent in (4b) are distinguished in the semantic representation, though they can have the same referent in the world. On the other hand, the reflexive and its antecedent in (4a) must be identical both in their real world referents and in the semantic representation.

\subsection{Comparative Constructions}

As stated above, pure reflexives, represented as a pure variable $\mathrm{x}$, identify the same entity in the world as their antecedents do, whereas near-reflexives, represented as a function $\mathrm{f}(\mathrm{x})$, do not require complete identity with their antecedents; the referent of a near-reflexive is related to the referent of its antecedent via its near-reflexive function. Lidz (2001a, b) points out that the semantic (representative) disparity between near- and pure-reflexives gives rise to an interpretive difference for comparative constructions. Consider first the Dutch cases, which exhibit an interesting behavior, as follows:

(5) a. zij verdedigde zichzelf beter dan Peter. she defended selfself better than Peter 'She defended herself better than Peter defended himself.'

'She defended herself better than Peter defended her.'

b. zij verdedigde zich better dan Peter. she defended self better than Peter 'She defended herself better than Peter defended himself.'

'*She defended herself better than Peter defended her.' 
(Lidz (2001a))

(5a) with the morphologically complex anaphor zichzelf allows both strict and sloppy readings, whereas (5b) with the simplex anaphor allows only a sloppy interpretation. This contrast cannot be explained unless we classify anaphors into two types. On the other hand, in English, where there is no simplex anaphor, generally VP-ellipsis constructions give us the two possible interpretations, sloppy and strict readings, as does the Dutch counterpart in (5a).

(6) John defended himself better than Mary did.

'John defended himself better than Mary defended herself.'

'John defended himself better than Mary defended him.'

Let us start with the derivation of the Dutch case with the simplex anaphor in (5b). The matrix predicate is semantically represented as in (7), where the arguments are converted into bound variables.

( 7 ) $\lambda x$ [defend $(x, x)]$

Copying this predicate to the deleted clause and applying the subject arguments then gives the representations in (8).

( 8 ) a. $\lambda x$ [defend $(x, x)]($ she) better than $\lambda x[$ defend $(x, x)]$ (Peter)

b. [defend (she, she)] better than [defend (Peter, Peter)]

(Lidz (2001a: 136))

For the Dutch sentence in (5a) and the English counterpart in (6) containing the complex anaphors, which allow two readings, the anaphors are given indices from their antecedents, or indices different from those of their antecedents. That is, in a sentence like (9a) two semantic representations are available as in $(9 b, c)$.

(9) a. John defended himself.

b. $\lambda x$ [defend $(\mathrm{x}, \mathrm{f}(\mathrm{x}))]\left(\mathrm{John}_{\mathrm{i}}\right)$

c. $\lambda x$ [defend $\left.\left(\mathrm{x}, \mathrm{f}_{\mathrm{i}}(\mathrm{x})\right)\right]\left(\mathrm{John}_{\mathrm{i}}\right)$

(Lidz (2001a: 136))

A near-reflexive is semantically represented as a function, not as a variable, and so taken to be an independent semantic argument, which is capable of bearing an index. The two possible readings for the Dutch sentence in (5a) and the English sentence in (6) are illustrated in (10), where (10a) represents a sloppy reading and (10b) represents a strict reading.
a. $\lambda x$ [defend $\left.\left(x, f_{i}(x)\right)\right]\left(\right.$ she $\left._{i}\right)$
better than $\lambda x$ [defend $\left.\left(x, f_{j}(x)\right)\right]\left(\right.$ Peter $\left._{j}\right)$
b. $\lambda x\left[\right.$ defend $\left.\left(x, f_{i}(x)\right)\right]\left(\right.$ she $\left._{i}\right)$ better than $\lambda x\left[\right.$ defend $\left.\left(x, f_{i}(x)\right)\right]($ Peter) 
The ambiguous interpretation observed in the case containing the complex anaphors can thus be attributed to the representative properties of the anaphors. If the anaphor is coindexed with its antecedent as in (10a), a sloppy reading will result. If the anaphor is given an index different from its antecedent as in $(10 \mathrm{~b})$, a strict reading will result. ${ }^{4}$

Returning to the Dutch case of (5a) with the pure-reflexive, it is easy to see that such coindexation as in (10) is not established, because the anaphor is not an independent semantic argument and so cannot bear an index. As a consequence, only a sloppy reading derives and a strict reading is excluded. Lidz's semantic classification of anaphors into two classes, then, will successfully capture the semantic asymmetry observed in comparative constructions. ${ }^{5,6}$

4 In Line with Lidz (2001a: 137), we assumed in an earlier draft that in a VPellipsis context containing a near-reflexive, if the anaphor is bound, a sloppy reading will result. As an anonymous reviewer points out, leaving $f(x)$ without an index does not make $f(x)$ bound by the lambda operator at the front of an expression-it is further required that $\mathrm{f}(\mathrm{x})=\mathrm{x}$. Then, we assume in this paper that rather than merely being bound, the anaphor establishes the dependency on its antecedent via coindexation for a sloppy identity reading.

5 In RR's (1993) framework, in which all reflexive-marked predicates are predicted to behave alike, of course, this contrastive behavior cannot be predicted. In this respect, Lidz's approach is superior to RR's, in which the two kinds of reflexive marking (lexical marking and SELF marking) are not separately classified, thus are taken to be semantically equivalent. In Lidz's framework, in which two classes of anaphors are semantically partitioned, the interpretive asymmetry is naturally explained.

6 Another interpretive distinction between morphologically complex anaphors and simplex ones has to do with the Madame Tussaud context, first discussed in Jackendoff (1992), in specific with whether a statue reading of anaphor is available. In Dutch, where there are two types of anaphors, the availability of a statue reading is limited to the morphologically complex anaphor zichzelf.

(i) a. ze zag zich in een griezelige hoek staan she saw self in a creepy corner stand 'She saw herself (=reflection, *statue) in a creepy corner stand'

b. ze zag zichzelf in een griezelige hoek staan she saw selfself in a creepy corner stand 'She saw herself (=reflection or statue) in a creepy corner stand' The interpretation for (ia) is that the person saw her own reflection in the mirror, whereas (ib), in addition, allows a reading which can be true if the person saw a statue portraying her. Thus, when the simplex zich appears, the statue reading is prohibited, while when the complex anaphor occurs, this reading is available. As stated in König and Siemund (2000), a similar distinction is expressed analogously in 


\subsection{Unresolved Issues in Lidz}

Even in Lidz's analysis, however, there remains a question to be resolved. In this section we will point out that not all English anaphors allow such coindexation as in (10). It has been found in the previous section that pure-reflexives allow only a sloppy interpretation while near-reflexives allow both strict and sloppy readings. Since English is assumed to have no pure-reflexive, it is natural to predict that comparative VP-ellipsis constructions generally allow both sloppy and strict readings:

(11) Mary defended herself better than John did.

'Mary defended herself better than John defended himself.'

'Mary defended herself better than John defended her.'

Contrary to this predication, however, the following examples, which are referred to as reflexive middles (cf. Fellbaum (1988)), allow only a sloppy reading, although the complex anaphor itself appears.

(12) a. Fact A explains itself more clearly than Fact B does.

'Fact A explains itself more clearly than Fact B explains itself.'

'Fact A explains itself more clearly than Fact B explains Fact A.'

b. Example A suggests itself more clearly than Example B does.

'Example A suggests itself more clearly than Example B suggests itself.'

'*Example A suggests itself more clearly than Example B suggests Example A.'

As Lidz argues, the blocking of a strict reading indicates the anaphor is a pure reflexive. This is a crucial requirement and we will point out

German and in many other languages. This interpretive distinction too can be explained from the representative properties between zich and zichself. Zichself, which introduces the near reflexive function, is not required to be identical to, but merely related to its antecedent. That is why it can refer to a different entity in the world, thus inducing the statue reading. On the other hand, in a pure-reflexive sentence (ia) the anaphor and its antecedent must be identical in the semantic representation. Of course, this requires the referents of the anaphor and its antecedent to be identical in the world as well: as a consequence, the statue reading is excluded. 
that the morphologically complex anaphor itself in (12) too should be classified as a pure reflexive on the basis of the discussion below. Lidz (2001a: 123) assumes that Reinhart and Reuland's SELF anaphors (morphologically complex anaphors) are near-reflexives, not requiring complete identity with their antecedents. Given this, of course itself in (12) too is not an exception and should be classified as a near-reflexive. However, the unitary interpretation shown in (12) requires us to reconsider the semantic representation of the predicates, explain and suggests. More specifically we would like to assume that certain anaphors that are referentially dependent on non-Agent antecedents are interpreted as pure variables in the semantics in Lidz's framework. In the following sections, we will give a natural account for the contrastive behavior observed in (11) and (12) by assuming a dichotomy between Agent and non-Agent subjects.

\section{Non-Agentive Subjects}

\subsection{Hasegawa (2001)}

Here, we would like to specify where Agent subjects and non-Agent subjects are syntactically posited. According to recent proposals such as Chomsky (1995, 1998, 2001) and Collins (1997), the external role is generated in Spec of $v \mathrm{P}$, not in Spec of VP. This differs substantially from the VP-Internal Subject Hypothesis (cf. Fukui (1986), Kitagawa (1986), Sportiche (1988)), which states that the external role is generated in Spec of VP. In the $v \mathrm{P}$ analysis, the $[v[\mathrm{VP}]]$ configuration entails a relation between two events where one is a proper subpart of the other, and causativity/transitivity is syntactically shown via a 'causative' light verb. Light $v$ introduces an external role and enters into a relation with the object ("Agree," or structural Case in Chomsky (1998, 2001)). Also, the semantic motivation for $v$ is to capture the observation that the external argument is not an argument of the verb, but rather, its interpretation is given compositionally by the verb phrase. It is important to note that $v \mathrm{P}$ as assumed in Chomsky is originally posited to represent 'causativity/transitivity,' not 'agentivity.' However, as claimed by Hasegawa (2001), it is more appropriate to assume that the semantic properties of $v$ indicate the presence of an Agent argument as an external argument. Given this, we can give a plausible account for a predicate that is unaccusative but with an Agent subject, as shown below: 
(13) a. Mary (intentionally) moved.

b. Susan stood straight.

a. Hanako-ga (wazato) ugoi-ta.

-Nom intentionally move-past

'Hanako moved (intentionally).'

b. Kyoko-ga (koini) taoreta.

-Nom on=purpose fall-past

'Kyoko fell on purpose.'

(Hasegawa (2001))

These examples, referred to as agentive unaccusatives, are naturally addressed by assuming that the subjects which are generated VP-internally are raised to Spec $v \mathrm{P}$, where they are assigned an agentive role. This analysis is based on the premise that Agent is structurally defined as an argument occupying Spec $v \mathrm{P}$. Likewise, it is also possible to account for the fact that passive subjects can behave as active subjects with respect to the secondary agentivity effect (cf. Osawa (2001)).

(15) a. Fred was carelessly arrested by the police.

b. Mary was intentionally seduced by Joe.

(Jackendoff (1972) cited in (Osawa 2001: 364))

Furthermore, ignoring the distinction between Agent and Non-Agent subjects exposes a problem with UTAH, as we stated at the outset of this article, and makes it impossible to give an appropriate account for several syntactic phenomena. The analysis of comparative constructions is also one such case.

Let us further see how plausible it is to assume that non-agentive subject roles are VP-internally assigned. Consider some of the nonagentive transitive sentences that Hasegawa exemplifies: (16) and (17) are sentences with a Causer of Psychological State; and (18) and (19) are sentences with an Experiencer or Patient of Sensation Expression.

(16) a. The news surprised everyone.

b. Her son worried Mary.

(17) a. Sono sirase-ga minna-o odorok-ase-ta. the news-Nom everyone-Acc surprised-cause-past 'The news surprised everyone.'

b. Sono uwasa-ga Hanako-o kurusim-e-te-i-ru. the rumor-Nom $\quad$-Acc be $=$ tormented-tr-prog-pres 'The rumor tormented Hanako.'

(18) a. Jane broke her $_{i}$ arm.

b. Sue $_{i}$ hurt her ${ }_{i}$ back. 
(19) a. Hanako-ga ude-o ot-ta.

-Nom arm-Acc break-past

'Hanako broke her arm.'

b. Tomoko-ga kosi-o itam-e-ta.

-Nom back-Acc hurt-tr-past

'Tomoko ${ }_{i}$ hurt her ${ }_{i}$ back.'

As pointed out by Hasegawa, these all have intransitive (or noncausative) counterparts.

(20) a. Everyone is surprised at the news.

b. Mary worried about her son.

a. Minna-ga sono sirase-ni odoroi-ta.

Everyone-Nom the news-Dat be $=$ surprised-past

'Everyone was surprised at the news.'

b. Hanako-ga sono uwasa-ni kurusin-de-iru.

-Nom that rumor-Dat be $=$ tormented-prog-pres

'Hanako is tormented with the rumor.'

(22) a. Jane's arm broke

b. My back hurt.

(23) Hanako-no ude-ga or-e-ta.

-Gen arm-Nom break-intr-past

'Hanako's arm broke. (these all from Hasegawa (2001))

The transitive subjects in (16) and (17) appear as an adjunct in (20) and (21) and those in (18) and (19) as a genitive phrase in (22) and (23). Interestingly, this type of transitive-intransitive alternation is confined to non-agentive sentences and cannot be observed in the case of agentive transitives.

(24) a. Jane opened the door.

b. *The door opened by/with Jane.

a. Syasyo-ga densya-o okur-ase-ta

Conductor-Nom train-Acc delay-tr-past

'The conductor delayed the train.'

b. *Densya-ga syasyo-de okur-e-ta.

Train-Nom conductor-by be $=$ delayed-intr-past

'The train was delayed by the conductor.'

(ibid.)

According to Hasegawa, this suggests that a non-agentive subject role in a transitive is assigned as an adjunct or a possessor DP of an unaccusative but is raised to the subject position in a transitive sentence.

One argument for the claim that the subject of a non-agentive transitive is raised from inside VP is relevant to the phenomenon of back- 
ward binding of anaphors, as exemplified below:

(26) a. The pictures of herself $f_{i}$ annoyed Mary $y_{i}$.

b. The rumor about himself $\mathrm{f}_{\mathrm{i}}$ worried $\mathrm{John}_{\mathrm{i}}$.

a. Zibun ${ }_{\mathrm{i}}$-ni tuite-no uwasa-ga Hanako $\mathrm{K}_{\mathrm{i}}-\mathrm{o}$

Self-about-Gen rumor-Nom -Acc

Kanasim-ase-ta.

be $=$ sad-cause-past

'The rumor about herself made Hanako sad.'

b. Zibun ino kako-ga Taro $_{\mathrm{i}}$-o

Self-Gen past-Nom -Acc

kurusim-e-te-i-ru.

be $=$ tormented-tr-prog-pres

'His past life distresses Taro.'

(ibid.)

Belleti and Rizzi (1988) posit that a subject of an Experiencer psychpredicate occurs below an object argument at D-structure. Similarly, Hasegawa accounts for the backward binding phenomena by claiming that the subjects of these causatives are raised from a position lower than the Experiencer objects and so the anaphors inside are bound within VP by the objects. ${ }^{7}$

Another argument for Hasegawa is observed as well in (28). The examples below show that the possessor of the object is not allowed to be phonologically represented: 8

(28)

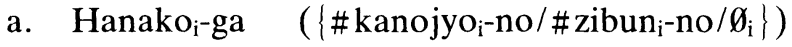
-Nom
ude-o ot-ta
arm-Acc break-past
'Hanakoi broke her arm.' $_{\mathrm{i}}$
b. Tomoko -ga $\left(\left\{{ }^{*}\right.\right.$ kanojyo $_{\mathrm{i}}$-no $/{ }^{*}$ zibun $_{\mathrm{i}}$-no $\left.\left./ \emptyset_{\mathrm{i}}\right\}\right)$ kosi-o
-Nom back-Acc
itam-e-ta.
hurt-tr-past
'Tomoko ${ }_{i}$ hurt her back.' $^{\prime}$
(ibid.)

7 Hasegawa (2001) does not give an explicit argument about the location of a Causer argument inside VP. She simply states that it is adjoined to $\mathrm{V}^{\prime}$, where it is c-commanded by the position of the Theme, Spec of VP. The view that a Theme argument is generated in Spec of VP originates in Hale and Keyser (1993).

8 \# means to be lacking in a non-agentive reading. 
The prohibition against the occurrence of a possessor in (28) under a non-agentive reading of the subject strongly suggests that the Experiencer subject is raised from the genitive possessive DP position within the object DP. In contrast, a possessor or a reflexive may sometimes occur if the subject is given an agentive interpretation. This is shown in (29), and can also be seen with an agentive interpretation of $(28 \mathrm{a})$.

(29) Hanako H $^{-g a} \quad\left(\left\{\right.\right.$ ?kanojyo $_{\mathrm{i}}-$ no $_{\text {zibun }}$-no $\left.\left./ \emptyset_{\mathrm{i}}\right\}\right)$

-Nom her-Gen/self-Gen

kao-o $\quad$ egai-ta/tatai-ta $\}$.

face-Acc draw-past/hit-past

'Hanako $\{$ drew/hit $\}\left\{\right.$ ?her $_{\mathrm{i}} /$ self $\left.\left._{\mathrm{i}} / \emptyset_{\mathrm{i}}\right\}\right)$ face.'

(ibid.)

Thus, Hasegawa claims that Agent subjects, unlike non-Agent ones, originally occupy the external position, i.e. the Spec of $v \mathrm{P}$. Since in the case of Agent subjects there is nothing (like a trace) in the possessive DP position due to the lack of Possessor Ascention, unlike in the case of non-Agent subjects, it is possible that genitive pronouns can appear, whether they are anaphoric on their subjects, or not. Furthermore, consider the English equivalent to (28), as exemplified below:

(30) a. Hanako broke her $_{\mathrm{i}}$ arm.

b. Tomoko ${ }_{i}$ hurt her back. .

In English, unlike in Japanese, possessives can appear in non-agentive transitives as well. Hasegawa argues that the pronouns in (30) which must be bound by the subjects on a non-agentive interpretation are traces or resumptive pronouns left after movement. Thus, it can be said that whereas Japanese requires a phonologically null possessive (trace), in English the trace has to be phonologically realized. ${ }^{9}$

For Hale and Keyser (1993), Chomsky (1995, 1998, 2000) and Collins (1997), in fact, transitive subjects in general are assumed to be posited in Spec of $v \mathrm{P}$, regardless of the $\theta$-role they bear. More precisely, they assume that non-Agent subjects too are assigned external roles. However, the foregoing discussion leads us to conclude that non-Agent

9 Hasegawa (2001) states that English, unlike Japanese, does not allow a null possessive due to the strong EPP or D feature on D, and that a trace is to be phonologically realized. Alternatively, along the lines taken by Chomsky $(1998,2001)$, it could be considered that the EPP feature is specified on the head of DP in English, but not in Japanese. 
subjects are VP-internal elements and should not be assigned external roles. Thus, Spec of $v \mathrm{P}$ in the case of non-agentive transitives is left unoccupied.

3.2. Agent Subjects and Non-Agent Subjects Asymmetry in Comparatives

With the discussion so far in mind, here again, let us return to the question why non-Agent subjects do not allow two readings whereas Agent subjects do, as shown in (11) and (12), repeated below:

(31) a. Fact A explains itself more clearly than Fact B does.

'Fact A explains itself more clearly than Fact B explains itself.'

'Fact A explains itself more clearly than Fact B explains Fact A.'

b. Example A suggests itself more clearly than Example B does.

'Example A suggests itself more clearly than Example B suggests itself.'

'*Example A suggests itself more clearly than Example B suggests Example A.'

(32) Mary defended herself better than John did.

'Mary defended herself better than John defended himself.'

'Mary defended herself better than John defended her.'

This unique behavior by non-Agent subjects will be accounted for by assuming that certain pronouns that are referentially dependent on nonAgent subjects are not genuine pronouns, but rather resumptive pronouns left in VP. Take a look at the matrix clauses in $(31 a, b)$.

(33) a. Fact A explains itself.

b. Example A suggests itself.

With the discussion in the previous section in mind, it seems appropriate to assume that Fact $A$ and Example $A$ have raised from within the VPs, and that the reflexive pronoun itself is a resumptive pronoun left after the movement of the subject to the Spec of TP. This assumption seems intuitively feasible, but, actually, is born out by the fact that anaphors in reflexive middles show different behaviors from genuine anaphors. Let us, then, compare what we consider as resumptive anaphors (34) and genuine anaphors (35).

(34) a. The fire rapidly spread itself through the wilderness.

b. These problems will solve themselves. 
(35) a. John shaved himself in the morning.

b. Bill defended himself from the enemy.

In (35) the predicates shave and defend each bear two thematic roles, one controlling the event, and the other experiencing it. In contrast, spread and solve in (34) are 1-place predicates with one semantic argument, which happens to be syntactically realized in two different positions. This is plausible also with respect to the fact that a resumptive anaphor cannot syntactically stand as an independent argument. First, note that a genuine anaphor is subject to Topicalization, while a resumptive anaphor is not.

(36) a. ?Himself, John shaved in the morning.

b. *Itself, the fire spread through the wilderness.

A second piece of evidence comes from coordination. Unlike a genuine anaphor, a resumptive anaphor is never coordinated with another object, as attested in $(37 \mathrm{a}, \mathrm{b})$.

(37) a. John shaved Bill and himself in the morning.

b. ${ }^{*}$ The fire spread heat and itself through the wilderness.

These suggest that a resumptive anaphor does not syntactically behave as one individual and is one of the two occurrences of a syntactic object. ${ }^{10}$

10 An anonymous reviewer points out that reflexive middles are treated on a par with what is considered as a lexically reflexive predicate, like behavior and pride, as exemplified in (i) and so can naturally be analyzed along the lines taken by RR (1993) and substantially followed by Lidz (2001a, b) under Condition R.

(i) a. Bill ${ }_{\mathrm{i}}$ always behaves himself $/{ }^{*}{ }^{*} \operatorname{him}_{\mathrm{j}} /{ }^{*}$ her.

b. $\mathrm{He}_{\mathrm{i}}$ prided himself $\mathrm{f}_{\mathrm{i}} /{ }^{*} \mathrm{him}_{\mathrm{j}} /{ }^{*}$ her on his ability.

No doubt, both explain and suggest in (33) and behavior and pride in the above examples bear a lexically reflexive meaning (although the former may be ambiguous between lexically reflexive and lexically non-reflexive), but it is still unclear that they are all naturally addressed in RR's and Lidz' frameworks. In RR's framework in which the lexical content of the anaphor determines its interpretations, how to interpret the examples in (33) and (i) is left open to question. Since RR identify morphologically complex anaphors with reflexivizers, those predicates are apparently reflexive-marked superfluously. In order to explain these examples, RR would have to say that SELF anaphors appearing in examples such as (33) and (i) are ambiguous between SELF anaphors and SE anaphors despite their morphological complexity.

Also, in Lidz's Condition R, as illustrated below, there still remain some issues, to be made clear.

(iii) $\lambda \mathrm{x}[\mathrm{P}(\mathrm{x}, \mathrm{x})] \longleftrightarrow(\theta 1=\theta 2)$ 
Let us, then, return to discussion of the interpretation in (31) and (32). In Lidz the anaphors itself in (31) and herself in (32) would both be categorized as near-reflexives, because Lidz does not draw a line among the English reflexives. He simply assumes that Reinhart and Reuland's (1993) SELF anaphors are near-reflexives and their SE anaphors, pure-reflexives. Reinhart and Reuland's partitioning of anaphors is based on their morphological properties, and so both himself and itself should be treated as SELF anaphors in Reinhart and Reuland, and as near-reflexives in Lidz, respectively. Thus, we would wrongly predict that the semantic representation in (38a) is identical in relevant respects with that in $(39 a)$.

(38) a. John defended himself.

b. $\lambda x[$ defend $(x, f(x))](J o h n)$

(39) a. Fact A explains itself.

b. $\lambda x$ [explain $(x, f(x))]($ Fact $A)$

Recall that a near-reflexive, being a semantic argument, not a pure variable, can be freely assigned an index. Copying the semantic representation of (39b) to the deleted clause for (31a) then results in two possible interpretations: that is, if the anaphor was given an index different from that of its antecedent, a strict reading would result; and

The left side of this formula depicts the semantic representation of reflexivity, and the right side depicts the $\theta$-grid of a lexically reflexive predicate. This formula ensures that only pure-reflexives impose an identity requirement between arguments (semantically reflexive), thus requiring that the two $\theta$-roles of the predicate be identified. However, as pointed out by Reuland (2001: 487), it is unclear how Condition $\mathrm{R}$ is to be interpreted. Lidz proposes that the two $\theta$-roles of the predicate be coindexed, but it is unclear what indices on $\theta$-roles are, or what it means for two roles to be coindexed. Furthermore, it is unclear whether this formula is applicable to the examples in (33) and (i). As long as English anaphors are assumed to be near-reflexives, Condition $\mathrm{R}$ does not apply in English. Lidz (personal communication) states that the examples in (i) may be problematic, although he avoids a specific argument partly because their argument structures are not clear. The clearest examples for inherently reflexive predicates in English (the case in which Condition $\mathrm{R}$ works) are those with no overt anaphor, say, John washed, or Mary dressed (cf. Lidz (2001b)). However that may be, we will have to discuss Lidz's Condition R extensively somewhere else. Also, for unambiguously reflexive predicates such as behave and pride, which generally take agentive subjects, and so have to be addressed separately from reflexive middles, unfortunately we do not have a clear argument at present. Extensive discussion will have to be conducted on the next occasion. 
if the anaphor was coindexed with its antecedent, a sloppy reading would result. This is illustrated in (40), where (40a) represents the strict reading and $(40 \mathrm{~b})$ represents the sloppy reading.

(40) Fact A explains itself more clearly than Fact B does.

a. $\lambda x$ [explain $\left(x, f_{i}(x)\right)$ ] (Fact $\left.A_{i}\right)$ more clearly than $\lambda x$ [explain $\left.\left(\mathrm{x}, \mathrm{f}_{\mathrm{i}}(\mathrm{x})\right)\right]($ Fact $\mathrm{B})$

b. $\lambda x$ [explain $\left(x, f_{i}(x)\right)$ ] $\left(\right.$ Fact $\left.A_{i}\right)$ more clearly than $\lambda x$ [explain $\left.\left(x, f_{j}(x)\right)\right]\left(\right.$ Fact $\left.B_{j}\right)$

This analysis wrongly predicts that (40) gives rise to two possible readings. However, it excludes the strict interpretation that is represented in the semantic formula of (40a). On the other hand, in our analysis the unitary interpretation in (40) is naturally predicted, because itself should be represented rather as a pure variable in the semantic formula. Along the lines of the discussion so far, since it is analyzed as a phonologically realized trace left within VP, it is both syntactically and semantically identical with its antecedent. It follows then that it is treated as a pure variable in the semantics, as is a simplex anaphor. Pure-reflexives are not independent semantic arguments but variables, so itself in (40) obtains its value only via being bound in the semantics by its antecedent, as illustrated in (41):

(41) $\lambda x$ [explain $(x, x)$ ] (Fact A) more clearly than $\lambda x$ [explain $(\mathrm{x}, \mathrm{x})]($ Fact $\mathrm{B})$

In sum, the availability of a strict reading has to do with whether the anaphor can be construed as a function. Along the lines taken by Lidz (2001a, b), basically the English reflexive is a function $f(x)$ which is interpreted as an approximation of $\mathrm{x}$ without being necessarily identical with its antecedent. However, the discussion in this section leads us to conclude that the reflexive itself in (31) (or (40)) should rather be construed as a resumptive pronoun appearing as a result of the movement of the subject, thus semantically interpreted as a pure variable. ${ }^{11,12}$

11 While we have taken it for granted that the subjects in reflexive middles are non-agentive, there is also an view that they are given agentive roles.

(i) a. Fact A explains itself.

b. Example A suggests itself.

c. This door closes itself.

According to Fellbaum (1988), the subjects in the above examples are Theme argu- 


\section{Inalienable Possession Anaphora}

Our analysis will extend straightforwardly to Inalienable Possession Anaphora and Idioms, which have been extensively discussed in Burzio (1991).

ments and at the same time bear the role of an Agent argument. This analysis is based on the fact that the class of verbs that can form reflexive middles must select not only for a Theme but also for an Agent argument. In other words, the verbs that occur in reflexive middle formation are permissible in so far as the Theme can be interpreted as an Agent. Transitive verbs, like rot, mold, corrode, which allow only a Causer argument in the subject position, but not an Agent argument, cannot form reflexive middles.

(ii) a. *His mother/All that sugar rotted Johnnie's teeth.

b. Johnnie's teeth rotted.

c. *Johnnie's teeth rotted themselves.

(Fellbaum (1988)) Also, reflexive middles, unlike plain middles like This book sells easily, are transitives and the Theme selected for by the verb occupies the place of the Agent that is usually associated with the verb. Taking these facts into consideration, Fellbaum claims that reflexive middle formation is permissible in so far as the Theme can be interpreted metaphorically as an Agent. More simply, agenthood is transferred to the Theme argument. This analysis itself is apparently feasible, but it remains unclear how the theta roles are assigned to the arguments, more specifically, how the subject is doubly assigned both a Theme and an Agent role and then, how the reflexive should be treated. One might suggest that similarly with the cases of agentive unaccusatives and agentive passives, the subject in a middle reflexive is raised to Spec $v \mathrm{P}$ where it is assigned an Agent role, although metaphorically. However, to pursue this possibility may be difficult, as an anonymous reviewer suggests. Needless to say, the subjects in (i) are not compatible with Agent-oriented adverbs, as shown in (iii), which suggests that we have to address middle reflexives separately from agentive unaccusatives and agentive passives.

(iii) ${ }^{*}$ The door closed itself intentionally.

(iv) a. John fell down intentionally.

b. Bill was seduced by Mary on purpose.

12 As argued in Reuland (2001: 481), the essence of SELF marking is the introduction of a function $\mathrm{f}(\mathrm{x})$ which is interpreted as an approximation of $\mathrm{x}$ without being necessarily identical. However, the appearance of SELF anaphors in middle reflexives is problematic, because clearly they behave like SE anaphors (pure-reflexives) in VP ellipsis contexts. SELF marking in middle reflexives does not force an introduction of a function. To address this issue, we can raise an assumption that SELF anaphors in English can be substituted for SE anaphors like zich in Dutch in some cases, particularly since in English there is no phonological instantiation for $\mathrm{SE}$ anaphors. It follows that the morphological properties of anaphors are not crucial factors for determining their semantic representations. No doubt, more extensive study will be required. 


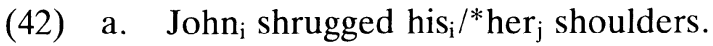

b. John ${ }_{\mathrm{i}}$ lost hisi $\mathrm{i}^{*}{ }^{*}$ her $\mathrm{j}$ way.

a. ${ }^{*}$ John shrugged his own shoulders.

b. *John lost his own way.

As shown in (42), the non-agentive subjects are required to corefer with the possessors. In addition, inherent contexts like this prohibit the complex form his own from appearing, as exemplified in (43). Thus, Burzio argues, on the basis of these examples, that inherently reflexive contexts favor simpler anaphors or pronouns (or no category) to express coreference. More specifically, the morphologically complex genitive his own is excluded in inherently reflexive contexts as in (43), so the simplex genitive his is required. The same is true of the Japanese counterpart. ${ }^{13}$

In Japanese a phonologically null form is used in an inherently reflexive context like (44), and the possessive zibun-no (self's) never appears. In the case of (44) which does not allow an additional meaning (an agentive reading), extra morphological material is excluded. Instead, a phonologically null pronoun is assumed to corefer with its antecedent.

Note that the following case too is considered as inherently reflexive, so that the complex possessive in (45b) apparently creates an unnatural interpretation.

(45) a. John opened his eyes.

b. \# John opened his own eyes.

However, with some additional context presumed, (45b) is not necessarily unacceptable, unlike (43). Roughly two interpretations strike us immediately: (i) John consciously opens his eyes, for example, because he faces a miserable scene and cannot help but close his eyes, but he has to open them to see the situation; and another interpretation

13 In Burzio (1994) complementarity between semantics and morphology in the expression of coreference is stated in a principle as in (i).

(i) Weak Anaphora Principle:

Inherent coreference $\longleftrightarrow$ Weak anaphora

(semantics)

(morphology) 
(ii), which may possibly be more conceivable, is that John opens the eyes of his own statue. In both cases, John is undoubtedly given an interpretation as Agent. What differentiates (45b) from (43) is that only (45b) makes an agentive reading available. ${ }^{14}$

The same fact is found in Japanese. The sentences in (46) show the same contrastive behavior in their interpretations as the English counterparts of (45) do.

(46) a. John-ga me-o aketa

John-Nom eye-Acc opened

'John opened his eyes.'

b. \# John-ga zibun-no me-o aketa

John-Nom self-Gen eye-Acc opened

'John opened his own eyes.'

Unless (46b) is given an additional context, then its interpretation is awkward, as is the case with (45b). Here too, basically an agentive reading is required for the subject John, or otherwise it will be taken as unnatural. Notice that both in English and in Japanese the appearance of complex possessives, that is, his own in English and zibun-no in Japanese, respectively, force an agentive reading. ${ }^{15}$

Recall the discussion in Section 3.1, based on Hasegawa (2001), where a non-agentive subject role in a transitive is assigned as a possessor DP of an unaccusative but is raised to the subject position in a tran-

14 An anonymous reviewer points out that the subjects in (45) should be taken as Agents, not as non-Agents. It is no doubt that an agentive interpretation is available, but we still claim that they are principally taken as non-Agents unless a certain context is introduced. The human organism allows a trade-off between automatic process and conscious control. Whereas we cannot consciously control our hearts, breathing and eyeblinking are automatic processes that can be consciously controlled. However, it is no doubt that breathing and eyeblinking are unconsciously or mechanically done under normal conditions. Similarly, although it is subject to conscious control, opening one's eyes is considered as what is being done unconsciously under normal conditions. Of course, with some context presumed, John in (45) is interpreted as an Agent.

15 It is true that zibun-no and his own are important factors for deriving an agentive reading, but without them, it will still be possible, say, by putting an emphasis on the simple possessive his in English and the nominal me (eye) in Japanese. 
sitive sentence. (See (18), (19), (22), and (23).) ${ }^{16}$ Given this, the possessives that give rise to an inherently reflexive (non-agentive) interpretation are traces or resumptive pronouns left at the extraction site of the subject: they must be bound by the subjects. Of course, in Japanese the null possessive, being bound by the subject, is assumed to function in the same manner as the English simple possessive does. ${ }^{17}$

Keeping the discussion here in mind, let us move on to the comparative VP-ellipsis constructions containing possessives below.

(47) a. John opened his eyes earlier than Mary did.

'John opened his eyes earlier than Mary opened her eyes.'

'*John opened his eyes earlier than Mary opened his eyes.'

b. John opened his own eyes earlier than Mary did.

'John opened his own eyes earlier than Mary opened her eyes.'

'John opened his own eyes earlier than Mary opened his eyes.'

Our informants point out that the difference between (47a) and (47b) is obvious; that is, when the complex form his own appears as in (47b), a strict reading is easier to obtain. On the other hand, the example containing the ordinary genitive his, as in (47a), does not allow the strict reading. This difference is explained by shedding light on the representative properties of the possessives. Thus, in (47b) his own, being referentially dependent on the agentive subject John, can be treated as

16 An anonymous reviewer raises a question: What mechanisms ensure that all and only non-agent subjects appear VP-internally? This is ensured by UTAH. Also, as we have seen in Section 3.1, assuming that Agent is assigned in Spec $v \mathbf{P}$ gives plausible explanations for such issues as agentive unaccusatives and agentive passives.

17 As pointed out by an anonymous reviewer, we will have to make it clear whether there is a connection between reflexivity and agentivity. Being (inherently) reflexive does not necessary exclude an agentive context, as we can see in the examples (i) in footnote 10 . What we have to emphasize here is that the example in (45b) implies that one can open one's eyes only in the sense that one would open someone else's eyes (cf. Burzio (1994: 77)). In that respect, it is possible to admit that an availability of an agentive interpretation can suppress an inherently reflexive context. We need to investigate the connection between agentivity and reflexivity more in depth. But we will leave it to another occasion for reasons of space. 
an independent argument and so is represented as a function $f(x)$ in the semantic representation. In contrast, John in (47a) is given a nonagentive interpretation, so the possessive his is a resumptive pronoun left after the movement of John and is treated as a bound variable, not as an independent argument, as with itself in the previous section. In other words, (48a) has the semantic representation in (48b).

(48) a. John opened his eyes.

b. $\lambda x$ [open $(\mathrm{x}, \mathrm{x}$-eyes)] (John)

As illustrated in (48b), his construed as a bound variable obtains its value only via binding. Copying the semantic predicate in (48b) to the deleted clause for (47a) then results in the semantic representation of (49), which allows only a sloppy reading.

(49) $\lambda x$ [open ( $x, x$-eyes)] (John)

earlier than $\lambda \mathrm{x}$ [open ( $\mathrm{x}, \mathrm{x}$-eyes)] (Mary)

The matrix clause in (47b), in contrast, is assumed to have a semantic representation like $(50 \mathrm{~b})$.

(50) a. John opened his own eyes.

b. $\lambda \mathrm{x}$ [open $(\mathrm{x}, \mathrm{f}(\mathrm{x})$-eyes)] (John)

Since his own in this case can function as an independent semantic argument, it obtains its value via coindexation. The two possible readings for (47b) are illustrated in (51), where (51a) represents a sloppy reading and $(51 \mathrm{~b})$ a strict reading:

(51) a. $\lambda x$ [open $\left(x, f_{i}(x)\right.$-eyes $\left.)\right]\left(\mathrm{John}_{\mathrm{i}}\right)$ earlier than $\lambda \mathrm{x}$ [open $\left(\mathrm{x}, \mathrm{f}_{\mathrm{j}}(\mathrm{x})\right.$-eyes $\left.)\right]\left(\mathrm{Mary}_{\mathrm{j}}\right)$

b. $\lambda x$ [open $\left(\mathrm{x}, \mathrm{f}_{\mathrm{i}}(\mathrm{x})\right.$-eyes $\left.)\right]\left(\mathrm{John}_{\mathrm{i}}\right)$ earlier than $\lambda x$ [open $\left(x, f_{i}(x)\right.$-eyes $\left.)\right]$ (Mary)

The same is true of the Japanese counterparts. As argued in Hoji (1995), comparative ellipsis (CE) in Japanese provides a syntactic context akin to VP ellipsis (and CE) in English, in regard to the distribution of sloppy and strict identity readings. Given this, consider the following Japanese examples:

(52) a. John-ga $\varnothing$ me-o Mary yorimo sakini ake-ta John-Nom pro eye-Acc Mary than earlier open-past 'John opened his eyes earlier than Mary opened her eyes.'

'??John opened his eyes earlier than Mary opened his eyes.'

b. John-ga zibun-no me-o Mary yorimo sakini John-Nom self'-Poss eye-Acc Mary than early 
ake-ta

open-past

'John opened his own eyes earlier than Mary opened her eyes.'

'?John opened his own eyes earlier than Mary opened his eyes.'

With the discussion on the English counterparts in (47) in mind, the zero form $(\emptyset)$ is represented as a bound variable whereas zibun-no (self's) is assumed to be a semantic argument that is representationally illustrated as a function $\mathrm{f}(\mathrm{x})$. Unlike zibun-no that generally gives rise to an agentive reading, the zero form which is dependent on a nonagentive subject should be considered as a trace. Given these things, the interpretive difference between (52a) and (52b) is accounted for in a plausible way. As explained in the English case of (47) above, the zero form is represented as a bound variable and so is given the interpretation (sloppy reading) only via binding. In contrast, zibun-no (self') is a function $\mathrm{f}(\mathrm{x})$, thus allowing the two possible interpretations via coindexation.

To strengthen our argument, let us see the examples below. Here again, we will see that the interpretive difference is caused by the difference of the representative properties.

(53) a. John exposed his fault earlier than Mary did.

'John exposed his fault earlier than Mary exposed her fault.'

'?(?)John exposed his fault earlier than Mary exposed his fault.'

b. John exposed his own fault earlier than Mary did.

'John exposed his fault earlier than Mary exposed her fault.'

'John exposed his fault earlier than Mary exposed his fault.'

(54) a. John-ga $\varnothing$ ketten-o Mary yorimo sakini

John-Nom pro fault-Acc Mary than earlier arawani-sita

exposure-did

'John exposed his fault earlier than Mary did.'

'John exposed his fault earlier than Mary exposed her fault.'

'??John exposed his fault earlier than Mary exposed his 
fault.'

b. John-ga zibun-no ketten-o Mary yorimo sakini

John-Nom self's fault-Acc Mary than earlier arawani-sita

exposure-did

'John exposed his fault earlier than Mary did.'

'John exposed his fault earlier than Mary exposed her fault.'

'John exposed his fault earlier than Mary exposed his fault.'

These are explained in the same manner as in (49) and (51). In English, only the example (53b) with the complex possessive allows two possible readings. Similarly, in the Japanese case, only the example (54b) where the possessive is phonologically realized makes two readings available. ${ }^{18}$ Along the lines we have taken so far, it is reasonable to assume that the simplex possessive his and the Japanese zero form are resumptive pronouns and so are interpreted as variables, whereas the complex possessives his own and zibun-no are independent arguments which are capable of bearing indices. The two readings for (53b) and (54b) are explained with the representations in (55) and (56).

(55) $\lambda x$ [expose $\left(x, f_{i}(x)\right.$-faults $)\left(\mathrm{John}_{i}\right)$ earlier than $\lambda x$ [expose $\left(x, f_{j}(x)\right.$-faults)] $\left(\right.$ Mary $\left._{j}\right)$ (sloppy reading)

(56) $\lambda x$ [expose $\left(x, f_{i}(x)\right.$-faults $)\left(J_{o h n}\right)$ earlier than $\lambda \mathrm{x}$ [expose $\left(\mathrm{x}, \mathrm{f}_{\mathrm{i}}(\mathrm{x})\right.$-faults)] (Mary) (strict reading)

In (55) where the possessive in the VP ellipsis context is given an index from its antecedent, the sloppy reading results, and in (56) where the anaphor is given an index from the matrix subject, the strict reading results. On the other hand, the unitary reading for (53a) and (54a) is given an explanation by assuming that the simplex possessive in English and the zero form in Japanese are pure variables, as we have seen in

18 Following Hiroaki Tada (personal communication), I substituted the predicate arawani-suru (exposure-do) for rotei-suru (exposure-do), which was used in an earlier draft. Rotei-suru is typically or conventionally non-other directed, so a strict reading seems rather difficult to derive. Arawani-suru is more capable of denoting other-directed situation. See König and Siemund (2000) for discussion as to otherdirected and non-other directed predicates. 
(47a) and (52a). ${ }^{19}$

\section{Conclusion}

In this paper we have defended Hasegawa's (2001) claim that while only agentive subjects are structurally defined as external arguments, non-agentive subjects occur VP-internally, by shedding light on the contrastive behavior between Agent subjects and non-Agent ones in comparative VP ellipsis. Throughout this article, it has been argued that certain pronouns that are anaphoric on non-Agent subjects should be taken as resumptive pronouns left after the movement of the subjects. Consequently, such pronouns are taken as pure variables in the semantics and so given their interpretation only via binding, thus resulting in a sloppy reading in VP ellipsis. But, needless to say, evidently more needs to be investigated than has been studied in this paper to clarify the properties of resumptive pronouns and sufficient conditions for identifying a pronoun as resumptive.

\section{REFERENCES}

Belletti, Adriana and Luigi Rizzi (1988) "Psych-verbs and $\theta$-theory," Natural Language and Linguistic Theory 6, 291-352.

Burzio, Luigi (1991) "The Morphological Basis of Anaphora," Journal of Linguistics 27, 81-105.

Burzio, Luigi (1994) "Weak Anaphora," Paths Towards Universal Grammar, ed. by Guglielmo Cinque, 59-84, Georgetown University Press, Washington, D.C.

Chomsky, Noam (1995) The Minimalist Program, MIT Press, Cambridge, MA. Chomsky, Noam (1998) Minimalist Inquiry: The Framework, MIT Occasional Papers in Linguistics 15, MIT Working Papers in Linguistics.

Chomsky, Noam (2001) "Derivation by Phase," Ken Hale: A Life in Language, ed. by Michael Kenstowicz, 1-52, MIT Press, Cambridge, MA.

19 The strict reading is available in (53a) and (54a) as well, only when the subjects are taken as Agent. The fluctuation of the judgement must be related to whether the subjects are read as Agent or not. In any case, if the subjects are interpreted as Agent, then both strict and sloppy readings result. 
Collins, Chris (1997) Local Economy, MIT Press, Cambridge, MA.

Fellbaum, Christiane (1988) "On the 'Reflexive Middle' in English," CLS 25, 123-132.

Fukui, Naoki (1986) A Theory of Category Projection and Its Application, Doctoral dissertation, MIT.

Hale, Kenneth and Samuel Jay Keyser (1993) "On Argument Structure and the Lexical Expression of Syntactic Relations," The View from Building 20: Essays in Linguistics in Honor of Sylvain Broberger, ed. by Kenneth Hale and Samuel Jay Keyser, 53-109, MIT Press, Cambridge, MA.

Hasegawa, Nobuko (2001) "Causatives and the Role of $v$ : Agent, Causer, and Experiencer," Proceedings of the COE International Symposium, ed. by Kazuko Inoue and Nobuko Hasegawa, 1-35, Kanda University of International Studies, Tokyo.

Hoji, Hajime (1996) "Sloppy Identity and Formal Dependency," WCCFL 15, 209-223.

Jackendoff, Ray (1992) "Mme. Tussaud meets the binding theory," Natural Language and Linguistic Theory 10, 1-31.

Kitagawa, Yoshihisa (1986) Subjects in Japanese and English, Doctoral dissertation, University of Massachusetts, Amherst.

König, Ekkehard and Peter Siemund (2000) "Intensifiers and Reflexives; A Typological Perspective," Reflexives: Forms and Functions, ed. by Zygmunt Frajzyngier and Traci S. Curl, 41-74, John Benjamins, Amsterdam.

Lidz, Jeffrey (2001a) "Condition R," Linguistic Inquiry 32, 123-140.

Lidz, Jeffrey (2001b) "Anti-antilocality," Syntax and Semantics 33: Long-Distance Reflexives, ed. by Peter Cole, Cabriella Hermon and C.-T. James Huang, 227-254, Academic Press, San Diego.

Nishiyama, Kunio (2000) "Zitakotai to Keitairon (Intransitive-Transitive Alternation and Morphology)," Nichieigo no Zita no Kotai (Intransitive-Transitive Alternations in Japanese and English), ed. by Tadao Maruta and Kazuyoshi Suga, 145-166, Hituzi Syobo, Tokyo.

Osawa, Satoko (2001) "Voice Specification in Phrase Structure," English Linguistics 18, 356-377.

Reinhart, Tanya and Eric Reuland (1993) "Reflexivity," Linguistic Inquiry 24, 657-720.

Reuland, Eric (2001) "Primitives of Binding," Linguistic Inquiry 32, 439-492.

Sporiche, Dominique (1988) "A Theory of Floating Quantifiers and Its Corollaries for Constituent Structure," Linguistic Inquiry 19, 425-449.

Kurume Institute of Technology

2228 Kamitsu, Kurume-shi

Fukuoka 830-0052

e-mail:fmohri@cc.kurume-it.ac.jp 